\title{
Flora arbórea na FLONA do Jamari, Rondônia
}

\author{
Arboreal flora in Jamari FLONA, Rondônia \\ Flora arbórea en Jamari FLONA, Rondônia
}

\section{Resumo}

O presente trabalho teve por objetivo caracterizar a composição e a estrutura de espécies da flora arbórea ocorrentes em uma unidade de conservação de uso sustentável, a Floresta Nacional (FLONA) do Jamari, em Rondônia. A unidade de conservação está inserida no Bioma Amazônia, considerado como um dos biomas de maior biodiversidade. Os dados foram coletados em 17 parcelas de 50 × $100 \mathrm{~m}$ (8,5 ha) onde avaliou-se a vegetação com $\mathrm{DAP} \geq 10,0 \mathrm{~cm}$. Gerou-se a composição florística, a diversidade pelo Índice de Shannon (H') e equabilidade de Pielou (J), os parâmetros fitossociológicos e estoques por classe de DAP. Foram identificadas 151 espécies, distribuídas em 34 famílias. As famílias com maior riqueza foram Fabaceae, Moraceae e Lecythidaceae. A diversidade de espécies foi considerada alta e uniforme $\left(\mathrm{H}^{\prime}=3,87 ; \mathrm{J}=0,77\right)$. Houve dificuldades na identificação das espécies florestais. Portanto, enfatiza-se a importância de investimentos em pesquisas voltadas para essa área. Protium robustum; Peltogyne paniculata; Pouteria torta, Tachigali spp., Eschweilera spp. e Inga spp. representaram o maior percentual de valor de importância e estoques na floresta. O maior estoque em densidade de árvores, área basal e volume se concentrou nas árvores com DAP $<50 \mathrm{~cm}$. De forma geral, a FLONA do Jamari se configura como importante Unidade de Conservação para o estado de Rondônia e Brasil, por conter uma biodiversidade da flora arbórea amazônica considerável e de grande valor ecológico e comercial.

Palavras-chave: Unidade de conservação; Parâmetros fitossociológicos; Diversidade florística.

\begin{abstract}
The present work aimed to characterize the composition and structure of tree species in the Jamari National Forest (FLONA), Rondônia. This information is an important tool for planning and conservation in tropical forests. The study was carried out at the Forest Management Unit III, in 17 plots of 50 x $100 \mathrm{~m}$ (total 8.5 ha), where the vegetation was sampled with $\mathrm{DBH} \geq 10.0 \mathrm{~cm}$. The richness and floristic composition were verified using the Shannon diversity index ( $\left.\mathrm{H}^{\prime}\right)$ and Pielou's equability $(\mathrm{J})$, and the phytosociological parameters and stocks by DAP class. The floristic composition was represented by 151 species, distributed in 34 families. The most important botanical families were Fabaceae, Moraceae and Lecythidaceae. Species diversity is considered to be high and uniform $\left(\mathrm{H}{ }^{\prime}=3.87 ; \mathrm{J}=0.77\right)$. The identification of forest species represented a problem in the forest inventory, and it is important to invest in research focused on this area. Protium robustum; Peltogynepaniculata; Pouteria torta, Tachigali spp., Eschweilera spp. and Inga spp. represent the highest percentage of importance value and stocks in the forest. The largest stock in tree density, basal area and volume is concentrated in trees with DBH below $50 \mathrm{~cm}$. In general, the Jamari FLONA is
\end{abstract}


configured as an important Conservation Unit for the state of Rondônia and Brazil, as it contains a considerable biodiversity of the Amazonian tree flora and of great ecological and commercial value.

Keywords: Conservation unit; Phytosociological parameters; Floristic diversity.

\section{Resumen}

Este estudio tuvo como objetivo caracterizar la composición y estructura de las especies arbóreas presentes en una unidad de conservación de uso sostenible, el Bosque Nacional de Jamari (FLONA) en Rondônia. La unidad de conservación se inserta en el Bioma Amazónico, considerado como uno de los biomas con mayor biodiversidad. Los datos se recogieron en 17 parcelas de 50 x $100 \mathrm{~m}$ (8.5 ha), donde se muestreó la vegetación con DAP $\geq 10.0 \mathrm{~cm}$. La riqueza y composición florística se verificaron mediante el índice de diversidad de Shannon $\left(\mathrm{H}^{\prime}\right)$ y la igualdad de Pielou (J), y los parámetros fitosociológicos y stocks por clase DAP. La composición florística estuvo representada por 151 especies, distribuidas en 34 familias. Las familias botánicas más importantes fueron Fabaceae, Moraceae y Lecythidaceae. La diversidad de especies se considera alta y uniforme $(\mathrm{H} '=3,87 ; \mathrm{J}=0,77)$. La identificación de especies forestales representó un problema en el inventario forestal, y es importante invertir en investigaciones enfocadas en esta área. Protium robustum; Peltogyne paniculata; Pouteria torta, Tachigali spp., Eschweilera spp. e Inga spp. representan el mayor porcentaje de valor de importancia y existencias en el bosque. La mayor población en densidad de árboles, área basal y volumen se concentra en árboles con DAP por debajo de $50 \mathrm{~cm}$. En general, el Jamari FLONA se configura como una Unidad de Conservación importante para el estado de Rondônia y Brasil, ya que contiene una considerable biodiversidad de la flora arbórea amazónica y de gran valor ecológico y comercial.

Palabras clave: Unidad de conservación; Parámetros fitossociológicos; Diversidad florística.

\section{Introdução}

As Unidades de Conservação (UC's) são espaços territoriais compreendidos pelos seus recursos ambientais e as águas jurisdicionais, legalmente instituídas pelo Poder Público, com objetivos de conservação e limites definidos, sob regime especial de administração, ao qual se aplicam garantias adequadas de proteção (Brasil, 2000). Esses espaços asseguram a representatividade de amostras, das diferentes populações de fauna e flora e habitats, preservando o patrimônio biológico existente, e ainda propiciam o desenvolvimento de atividades econômicas sustentáveis das comunidades do entorno (MMA, 2012). No Brasil existem 2.309 UC's, englobando Federais, Estaduais e Municipais, distribuídas entre os diversos biomas brasileiros (MMA, 2018). Os Biomas (Amazônia, Mata Atlântica, Cerrado, Caatinga, Pantanal e Pampa) por sua vez, decorrem de gradientes climáticos que levam a grandes variações ecológicas e faz com que o país seja detentor da maior diversidade de espécies do mundo (Veloso et. al, 1991; Zappi et al. 2012; MMA, 2021).

A fitossociologia é o estudo que permite quantificar e avaliar essa grande diversidade da flora, por meio de dados sobre a estrutura da comunidade vegetal, organizada por famílias, gêneros e espécies hierarquizadas em ordem de Valor de Importância (VI). O VI é determinado por meio dos valores relativos de densidade, frequência e dominância (Moro \& Martins, 2011). Por meio desses parâmetros, é possível caracterizar a biodiversidade da flora local e o grau de conservação dos ecossistemas naturais, sendo informações importantes para delimitar políticas de uso e conservação, principalmente se tratando de unidades de conservação de uso sustentável, como as florestas nacionais (FLONAs).

A FLONA do Jamari se localiza em Rondônia e foi criada em 25 de setembro de 1984, por meio do Decreto ${ }^{\circ}$ 90.224/84, sendo classificada como Unidade de Conservação de Uso Sustentável (MMA, 2005). Em 2007, se configurou como a primeira Unidade de Conservação do Brasil a fazer a parte da implementação de concessão florestal, que compreende um modelo de gestão de florestas públicas, em que o governo pode conceder às empresas e comunidades, o direito de manejar essas áreas explorando a madeira e produtos não madeireiros, além de oferecer serviços de turismo (Brasil, 2006). Esse modelo de gestão é previsto na Lei de Gestão de Florestas Públicas n 11.284/06 (Brasil, 2006; SFB, 2020).

Na FLONA do Jamari, dados oficiais publicados acerca da composição e estrutura das espécies arbóreas datam de 1983, que referem-se aos dados obtidos do inventário florestal realizado pelo Instituto Brasileiro de Desenvolvimento Florestal 
(IBDF), disponível no site do Serviço Florestal Brasileiro (SFB) (SFB, 2016). E dados mais atuais da vegetação da FLONA são obtidos nos planos de operação anual (POA) das empresas concessionárias, também disponíveis no site do SFB e em trabalhos científicos (Arêdes, 2017; Bueno, 2017). No entanto, a vegetação caracterizada nesses últimos documentos trata apenas das espécies comerciais com DAP $\geq 40,0 \mathrm{~cm}$. No trabalho de Jacobsen et al. (2020), é possível encontrar informações para outros grupos de espécies e com DAP $\geq 10,0 \mathrm{~cm}$, porém o trabalho trata da fitossociologia como ferramenta para a avaliação de impactos na vegetação pós-exploração, abordando a questão de danos na vegetação remanescente.

Assim, estudos focados na composição e estrutura das espécies arbóreas, sejam de valor comercial ou de importância para a manutenção dos serviços ecossistêmicos da floresta se fazem necessários para o sucesso do manejo florestal sustentável e da conservação dos recursos naturais. Dessa maneira, o objetivo deste estudo foi caracterizar a flora arbórea ocorrente na Floresta Nacional do Jamari, em Rondônia (RO), Brasil.

\section{Metodologia}

\subsection{Localização e caracterização da área}

O inventário foi realizado no ano de 2018, na Unidade de Manejo Florestal III (UMF III), na Floresta Nacional do Jamari, no estado de Rondônia (Figura 1).

Figura 1. Localização da Unidade de Manejo Florestal (UMF) III, FLONA do Jamari e das parcelas permanentes na UPA 1, UPA 2 e UPA 14.

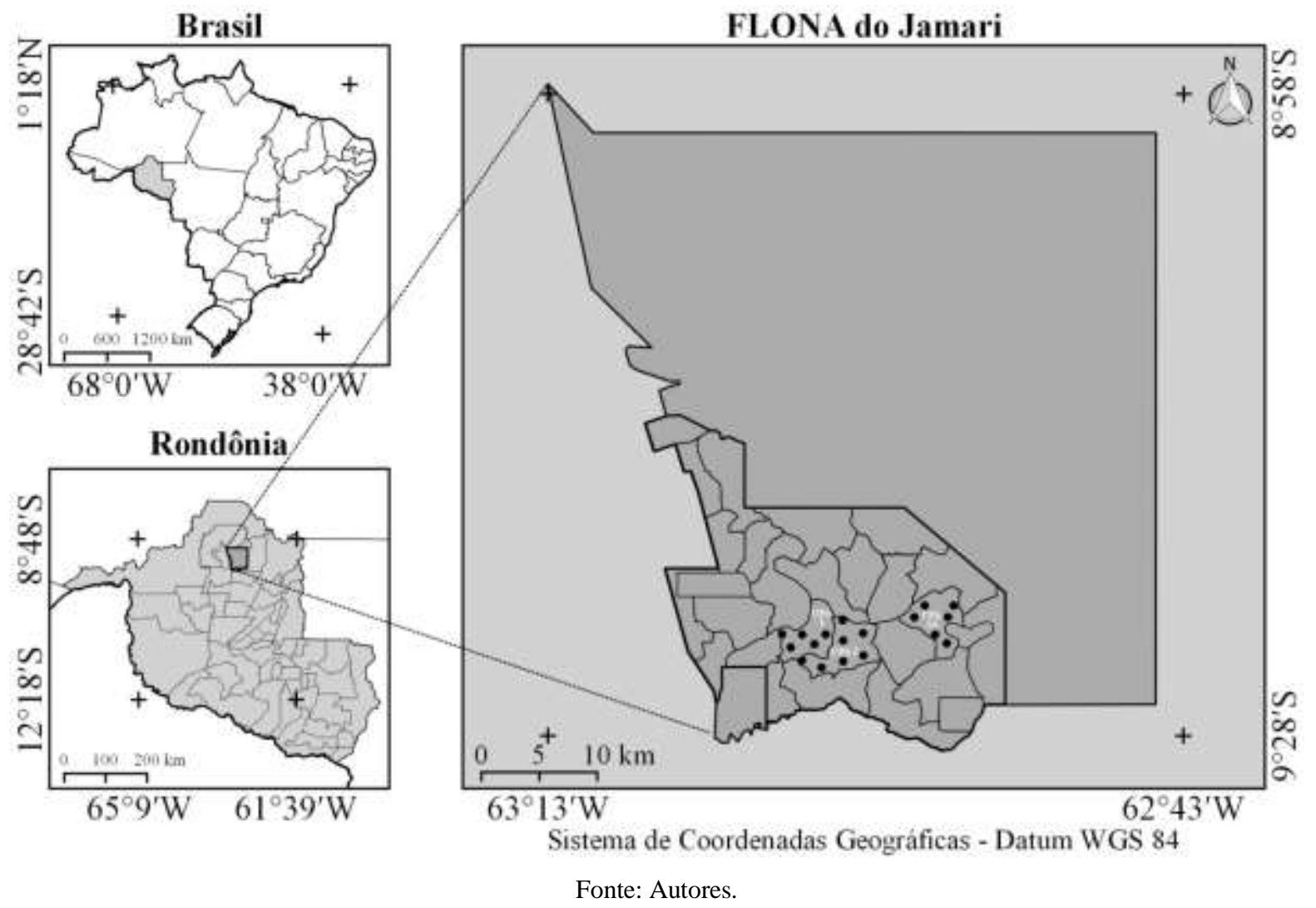

O clima da região é do tipo Am (monção), com média anual de temperatura variando entre 24 a $26{ }^{\circ} \mathrm{C}$ e período seco bem definido de junho a agosto (SEDAM, 2012; Alvares, et al., 2013). O relevo da área compreende 87,7\% com altitude inferior a 150 metros e 12,2\% em altitude superior a 150 metros (AMATA, 2007). O solo foi caracterizado em duas classes: 
Latossolos e Argissolos, com predomínio do Argissolo Vermelho-Amarelo distrófico (MMA/IBAMA, 2005).

A vegetação predominante é de Floresta Ombrófila Aberta Submontana, caracterizada como um tipo de vegetação de transição entre a Floresta Amazônica e as áreas extras amazônicas (Veloso, Rangel-Filho \& Lima, 1991; IBGE, 1992), podendo ainda, ocorrer com faciações da Floresta Ombrófila Densa Submontana e predominância de palmeiras ou cipós (MMA/IBAMA, 2005).

Os dados foram obtidos de parcelas permanentes, distribuídas de forma aleatória em três unidades de produção anual (UPA) (Tabela 1) na Unidade de Manejo Florestal III (Figura 1). A metodologia adotada para a marcação e medição das parcelas permanentes seguiu as orientações técnicas previstas nas Diretrizes Técnicas para instalação e medição de parcelas permanentes em florestas naturais do Bioma Amazônia (Silva, et al., 2005).

Tabela 1. Área e número de parcelas permanentes em que foi realizado o inventário florestal das unidades de produção anual na Unidade de Manejo Florestal III, FLONA do Jamari, RO.

\begin{tabular}{cccccc}
\hline & UPA & \multicolumn{3}{c}{ Parcela } & \multirow{2}{*}{ F } \\
\cline { 1 - 4 } $\mathbf{N}$ & Área (ha) & Quantidade & Área total (ha) & \\
\hline 1 & 1.359 & 5 & 2,5 & $0,18 \%$ \\
2 & 1.743 & 6 & 3,0 & $0,17 \%$ \\
14 & 1.316 & 6 & 3,0 & $0,23 \%$ \\
\hline Total & $\mathbf{4 . 4 1 8}$ & $\mathbf{1 7}$ & $\mathbf{8 , 5}$ \\
\hline
\end{tabular}

F = Fração de amostragem. Fonte: Autores.

No levantamento florístico/fitossociológico foram amostrados todos os indivíduos com DAP $\geq 10,0 \mathrm{~cm}$ em parcelas de 50 x $100 \mathrm{~m}$. Mediu-se o diâmetro a altura do peito (DAP) e a altura total das árvores amostradas. Além disso, realizou-se a coleta de material botânico das espécies para confecção de exsicatas, e posteriormente identificação, segundo Angiosperm Phylogeny Group (Chase, et al., 2016).

De posse dos dados gerou-se a riqueza florística, análise da similaridade entre as unidades amostrais em termos de composição de espécies, pelo índice de Jaccard (Souza \& Soares, 2013) e a diversidade, determinada pelo Índice de Shannon (H’) (Felfili \& Venturoli, 2000; Townsend, Begon \& Harper, 2006).

A análise estrutural foi representada pelos parâmetros fitossociológicos densidade, dominância, frequência e o valor de importância (Martins, 1991; Felfili \& Venturoli, 2000) e estrutura paramétrica, utilizando os estoques em densidade (ind ha${ }^{1}$ ), área basal $\left(\mathrm{m}^{2} \mathrm{ha}^{-1}\right)$ e volume $\left(\mathrm{m}^{3} \mathrm{ha}^{-1}\right)$ por classe de DAP (intervalo de $10 \mathrm{~cm}$ ) (Souza \& Soares, 2013).

$\mathrm{O}$ volume foi calculado utilizando-se a equação do volume de entrada única, ajustada para as espécies exploradas na área de estudo (AMATA, 2014).

$$
v=0,9494-(0,0053 D A P)+\left(0,00086 D A P^{2}\right)
$$

Onde: $\mathrm{V}=$ volume com casca $\left(\mathrm{m}^{3}\right)$; DAP $=$ diâmetro a altura do peito, mensurado a 1,30 $\mathrm{m}$ de altura $(\mathrm{cm})$.

Os dados foram organizados em planilhas eletrônicas e analisados no Fitopac (Shepherd, 2010). 


\section{Resultados e Discussão}

Nas 17 parcelas estudadas, foram encontradas 3.670 árvores (431 ind ha ${ }^{-1}$ ) com DAP $\geq 10 \mathrm{~cm}$, destas, 494 não foram identificadas. Verificou-se a presença de 151 espécies distribuídas em 35 famílias botânicas (Tabela 2).

Tabela 2. Composição florística observada em parcelas permanentes na FLONA do Jamari - RO.

\begin{tabular}{|c|c|c|}
\hline Família & Espécies & Número de indivíduos \\
\hline \multirow{3}{*}{ Anacardiaceae } & Anacardium parvifolium Ducke & 2 \\
\hline & Anacardium sp. & 1 \\
\hline & Astronium lecointei Ducke & 30 \\
\hline \multirow{8}{*}{ Annonaceae } & Duguetia sp. & 5 \\
\hline & Guatteriadiscolor R.E.Fr. & 9 \\
\hline & Guatteriapteropus Benth. & 26 \\
\hline & Guatteria spp. & 19 \\
\hline & Onychopetalum amazonicum R.E.Fr. & 15 \\
\hline & Ruizodendron sp. & 2 \\
\hline & Xylopia nitida Dunal & 9 \\
\hline & Xylopia sericea A. St.-Hill. & 32 \\
\hline \multirow{6}{*}{ Apocynaceae } & Aspidosperma polyneuron Müll.Arg & 2 \\
\hline & Aspidosperma sp.1 & 7 \\
\hline & Aspidosperma spp. & 9 \\
\hline & Couma utilis (Mart.) Muell. Arg. & 7 \\
\hline & Geissospermum laeve (Vell.) Miers & 4 \\
\hline & Himatanthus revolutus (Huber) Spina \& Kinoshita & 1 \\
\hline \multirow{5}{*}{ Bignoniaceae } & Anemopaegma sp. & 1 \\
\hline & Anemopaegma sp.1 & 2 \\
\hline & Anemopaegma spp. & 5 \\
\hline & Jacaranda copaia (Aubl.) D.Don. & 2 \\
\hline & Tabebuia incana A.H. Gentry & 10 \\
\hline Bixaceae & Bixa arborea Huber & 2 \\
\hline Boraginaceae & Cordia goeldiana Huber & 6 \\
\hline \multirow{4}{*}{ Burseraceae } & Protium heptaphyllum (Aubl.) Marchand & 10 \\
\hline & Protium robustum (Swart) D.M. Porter & 405 \\
\hline & Protium sagotianum Marchand & 1 \\
\hline & Trattinnickia rhoifolia Willd. & 15 \\
\hline \multirow{2}{*}{ Caryocaraceae } & Caryocar pallidum A.C. Sm. & 3 \\
\hline & Caryocar villosum (Aubl.) Pers. & 2 \\
\hline Celastraceae & Goupia glabra Aubl & 4 \\
\hline \multirow{2}{*}{ Chrysobalanaceae } & Couepia bracteosa Benth. & 24 \\
\hline & Licania heteromorpha Benth. & 66 \\
\hline Clusiaceae & Platonia insignis Mart. & 3 \\
\hline \multirow{3}{*}{ Combretaceae } & Buchenavia eichler & 1 \\
\hline & Buchenavia parvifolia Ducke & 6 \\
\hline & Buchenavia sp. & 5 \\
\hline
\end{tabular}


Terminalia amazonica (J.F. Gmel). Exell

4

Hevea brasiliensis (Willd. ex A. Juss.) Müll. Arg.

Rhodothyrsus macrophyllus (Ducke) Esser

26

Euphorbiaceae

Sebastiania commersoniana (Baill.)

94

Anadenanthera colubrina (Vell.) Brenan

Andira trifoliolata Ducke

Apuleia leiocarpa (J. Vogel) J. F. Macbr.

Bauhinia sp.

Bowdichia nitida Spruce ex Benth.

Bowdichia sp.

Copaifera multijuga Hayne

Copaifera sp.

Dialium guianense (Aubl.) Sandwith

Dinizia excelsa Ducke

Diplotropis rodriguesii H.C. Lima

Dipteryx odorata (Aublet) Willd.

Dipteryx polyphylla (Huber) Ducke.

Enterolobium maximum Ducke

Enterolobium schomburgkii (Benth.) Benth.

Hymenaea courbaril L.

Hymenolobium heterocarpum Ducke

Hymenolobium sp.

Inga spp.

Fabaceae

Mimosa caesalpiniifolia Benth.

Ormosia sp.

Parkia multijuga Benth. $\quad 8$

Parkia nitida Benth $\quad 5$

Parkia pendula (Willd.) Benth. ex Walp.

Parkia sp.

$\begin{array}{lr}\text { Peltogyne paniculata } \text { Benth. } & 140\end{array}$

Peltogyne sp. 1

Peltogyne venosa (Vahl) Benth $\quad 1$

Platymiscium trinitatis Benth 1

Poecilanthe parviflora Benth. 1

$\begin{array}{ll}\text { Schizolobium parahyba (Vell.) Blake var.amazonicum (Huber ex Ducke) } & 19\end{array}$

Stryphnodendron pulcherrimum (Willd.) Hochr 7

Swartzia acuminata Willd $\quad 4$

$\begin{array}{ll}\text { Swartzia sp. } & 16\end{array}$

Tachigali chrysophylla (Poepp.) Zarucchi \& Herend. 12

Tachigali poeppigiana Tul. 5

Tachigali setifera (Ducke) Zarucchi \& Herend. 42

Tachigali spp. 119 
$\begin{array}{lr}\text { Tachigali subvelutina (Benth.) Oliveira-Filho } & 20\end{array}$

$\begin{array}{ll}\text { Vatairea fusca (Ducke) Ducke } & 10\end{array}$

Zygia racemosa (Duck) Barneby \& J. W. Grimes $\quad 25$

\begin{tabular}{|c|c|c|}
\hline Humiriaceae & Endopleura uchi (Huber) Cuatrec. & 6 \\
\hline Hypericaceae & Vismia guianensis (Aubl.) Choisy & 2 \\
\hline \multirow{2}{*}{ Lamiaceae } & Aegiphila integrifolia (Jacq.) Moldenke. & 6 \\
\hline & Vitex montevidensis Cham & 9 \\
\hline \multirow{5}{*}{ Lauraceae } & Beilschmiedia brasiliensis (Kosterm.) Kosterm. & 129 \\
\hline & Mezilaurus itauba (Meisn.) Taub. ex Mez. & 2 \\
\hline & Ocotea fragrantissima Ducke. & 1 \\
\hline & Ocotea nigrescens Vicent. & 7 \\
\hline & Ocotea sp. & 4 \\
\hline \multirow{9}{*}{ Lecythidaceae } & Bertholletia excelsa Humb. \& Bonpl. & 11 \\
\hline & Cariniana integrifolia Ducke. & 7 \\
\hline & Cariniana micrantha Ducke & 2 \\
\hline & Cariniana sp. & 3 \\
\hline & Couratari stellata A. C. Sm. & 27 \\
\hline & Eschweilera coriacea (DC.) S.A.Mori & 68 \\
\hline & Eschweilera ovata (Camb.) Miers. & 16 \\
\hline & Eschweilera spp. & 125 \\
\hline & Lecythis idatimon Aubl & 23 \\
\hline Malpighiaceae & Byrsonima crispa A.Juss. & 5 \\
\hline \multirow{8}{*}{ Malvaceae } & Apeiba echinata Gaertn. & 66 \\
\hline & Huberodendron swietenioides (Gleason) Ducke & 17 \\
\hline & Pseudobombax grandiflorum (Cav.) A.Robyns. & 7 \\
\hline & Sterculia chicha A.St.-Hil. & 8 \\
\hline & Sterculia exelsa Mart. & 4 \\
\hline & Sterculia spp. & 12 \\
\hline & Theobroma speciosum Willd. ex Spreng. & 27 \\
\hline & Theobroma subincanum Mart. & 13 \\
\hline Melastomataceae & Bellucia grossularioides (L.) Triana & 6 \\
\hline \multirow[t]{2}{*}{ Meliaceae } & Cedrela fissilis Vell. & 2 \\
\hline & Guarea trunciflora C.DC. & 62 \\
\hline \multirow{10}{*}{ Moraceae } & Bagassa guianensis Aubl. & 1 \\
\hline & Brosimum acutifolium Huber & 9 \\
\hline & Brosimum paraense Huber. & 7 \\
\hline & Brosimum rubescens Taub. & 14 \\
\hline & Castilla ulei Warb. & 11 \\
\hline & Clarisia racemosa Ruíz \& Pav. & 18 \\
\hline & Ficus sp. & 1 \\
\hline & Pseudolmedia laevis (Ruiz \& Pav.) J. F. Macbr. & 151 \\
\hline & Pseudolmedia spp. & 116 \\
\hline & Pseudolmedia sp. & 4 \\
\hline
\end{tabular}




\begin{tabular}{|c|c|c|}
\hline & Pseudolmedia sp.1 & 1 \\
\hline & Pseudolmedia sp.2 & 61 \\
\hline & Pseudolmedia sp.3 & 54 \\
\hline \multirow{4}{*}{ Myristicaceae } & Iryanthera grandis Ducke & 44 \\
\hline & Virola michelii Heckel & 55 \\
\hline & Virola surinamensis (Rol. ex Rottb.) Warb. & 25 \\
\hline & Virola theiodora (Spruce ex Benth.) Warb. & 27 \\
\hline Myrtaceae & Syzygium spp. & 1 \\
\hline $\mathrm{NI}$ & NI & 494 \\
\hline \multirow{2}{*}{ Olacaceae } & Coccoloba sp. & 1 \\
\hline & Minquartia guianensis Aublet. & 19 \\
\hline \multirow{2}{*}{ Rubiaceae } & Calycophyllum spruceanum (Benth.) K.Schum. & 5 \\
\hline & Cordiera concolor (Cham.) Kuntze & 3 \\
\hline \multirow{2}{*}{ Rutaceae } & Esenbeckia leiocarpaEngl. & 25 \\
\hline & Zanthoxylum rhoifolium Lam. & 4 \\
\hline Salicaceae & Laetia procera (Poepp.) Eichler & 3 \\
\hline \multirow{4}{*}{ Sapotaceae } & Manilkara huberi (Ducke) Stand & 3 \\
\hline & Pouteria guianensis Aubl. & 31 \\
\hline & Pouteria sp. & 1 \\
\hline & Pouteria torta (Mart.) Radlk. & 164 \\
\hline Simaroubaceae & Simarouba amara Aubl. & 6 \\
\hline \multirow{2}{*}{ Urticaceae } & Cecropia sp. & 12 \\
\hline & Pourouma bicolor Mart. & 7 \\
\hline \multirow{5}{*}{ Vochysiaceae } & Erisma cf. bicolor Ducke & 9 \\
\hline & Erisma fuscum Ducke & 5 \\
\hline & Qualea paraensis Ducke & 18 \\
\hline & Qualea spp. & 1 \\
\hline & Vochysia sp. & 1 \\
\hline
\end{tabular}

Fonte: Autores.

O índice de similaridade de Jaccard variou de 0,54 a 0,20 . A correlação cofenética $(0,84)$ indicou boa confiabilidade dos dados na geração do dendrograma.

Mueller-Dombois E Ellenberg (1974), relataram que duas ou mais áreas são consideradas similares em termos de composição florística quando apresentam pelo menos $25 \%$ de espécies comuns, como o observado nas parcelas 2 (UPA 1), 8 (UPA 2), 15 (UPA 14) e 16 (UPA 14). Assim, entende-se que as UPAs estudadas são similares em termos de composição, permitindo a análise conjunta das parcelas.

Os valores de riqueza e densidade total da amostra foram superiores aos verificados por Jacobsen et al. (2015), em um povoamento florestal no Parque municipal de Pimenta Bueno, RO, onde encontraram densidade de 417 ind ha $^{-1}$. Assim como o estudo de Bentes-Gama et al. (2009), realizado em um fragmento de floresta de terra firme, campo experimental da Embrapa de Porto Velho-RO, onde foram identificadas 30 famílias, 99 espécies e densidade de 258 ind ha $^{-1}$. Esses estudos foram realizados em Florestas Ombrófila Aberta, o que explica a semelhança. No entanto, as áreas comparadas representam ambientes fragmentados, em estágio de conservação menor que as áreas estudadas na FLONA do Jamari. 
Quando consideradas outras regiões do Bioma Amazônia, os resultados mostraram-se superiores aos observados na FLONA do Jamari. Alarcon E Peixoto (2007), encontraram densidade de 544 ind ha-1 distribuídos em 192 espécies e 43 famílias botânicas, porém, o trabalho incluía indivíduos com DAP $\geq 5 \mathrm{~cm}$. Silva et al. (2015), observaram densidade de 584 ind ha ${ }^{-1}, 53$ famílias e 264 espécies para indivíduos arbóreos com DAP $\geq 10 \mathrm{~cm}$, floresta densa de terra-firme, na Amazônia Central. Natividade et al. (2018), ao avaliarem a ocorrência de indivíduos com DAP $\geq 10 \mathrm{~cm}$ antes da exploração, na Floresta Nacional do Tapajós, observaram 382,5 ind ha-1 ${ }^{-1}$, sendo contabilizadas um total de 153 espécies.

$\mathrm{Na}$ amostra obtida na FLONA do Jamari, ressalta-se que 494 árvores não foram identificadas, indicando que a composição da área pode ser maior que o verificado até o presente momento. Assim, em termos de composição, a área estudada de floresta ombrófila aberta na FLONA pode ter riqueza próxima a de áreas de floresta densa.

A identificação de espécies florestais nativas tem sido um desafio na Amazônia, uma vez que a flora possui alta diversidade de espécies, grande extensão territorial e diferentes formações vegetais. Isso se agrava ainda pela falta de profissionais da área e escassez de literaturas específicas que permitam o acesso a esse conhecimento (Marchiori, 2007).

Brito Junior (2018), em estudo sobre identificação botânica na FLONA do Jamari cita que a coleta de material botânico com estruturas férteis se faz necessária para garantir a correta identificação nos inventários florestais. No entanto, essa atividade nem sempre é possível, pois além das árvores serem muito altas, tem-se o fato de não estarem em período reprodutivo durante as atividades de inventário florestal, o que dificulta os trabalhos de identificação botânica. Além disso, os mateiros da região conhecem as espécies madeireiras e as que ficam sem identificação, geralmente, são aquelas não conhecidas por usos madeireiros.

Ainda segundo Brito Junior et al. (2021), para as espécies amazônicas, o uso de características dendrológicas e organolépticas do caule, associadas às da anatomia do lenho se mostram uma alternativa para a correta identificação de espécies florestais quando não se dispõe de material botânico com estruturas reprodutivas. Diante disso, percebe-se a importância de trabalhos na área de identificação botânica na região e treinamento de equipes técnicas.

As famílias botânicas com maior riqueza de espécies foram Fabaceae, Moraceae, Lecythidaceae, Malvaceae e Annonaceae, representando juntas mais de $52 \%$ da riqueza identificada (Figura 2). Essas famílias também estão entre as que se destacaram em termos de densidade de plantas (Figura 3). Esse resultado mostra que a diversidade local está concentrada em poucas famílias. Ratificando a importância ecológica das mesmas ao equilíbrio faunístico e florístico da floresta (Matos \& Amaral, 1999). 
Figura 2. Famílias botânicas com maior riqueza de espécies observadas na Unidade de Manejo Florestal III, FLONA do Jamari - RO.

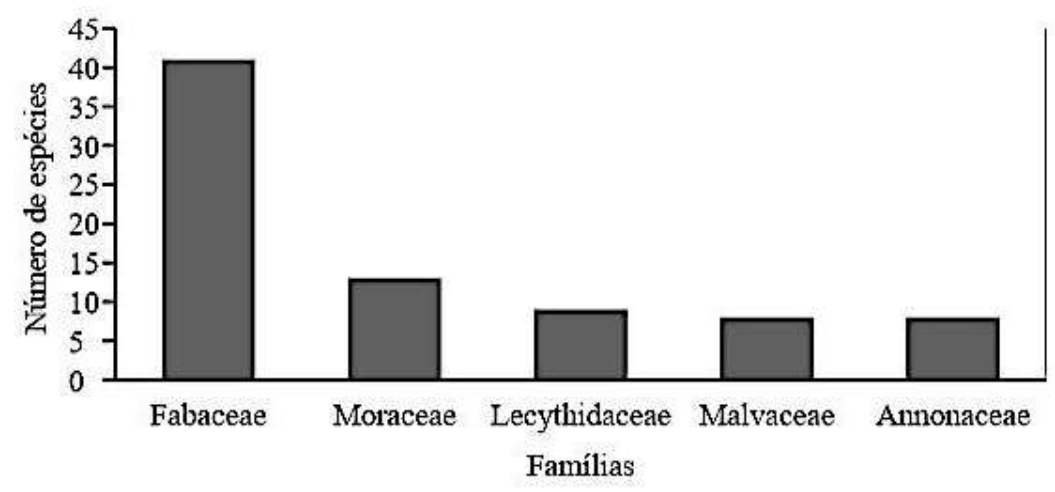

Fonte: Autores.

Figura 3. Famílias botânicas com maior número de indivíduos observadas na Unidade de Manejo Florestal III, FLONA do Jamari - RO.

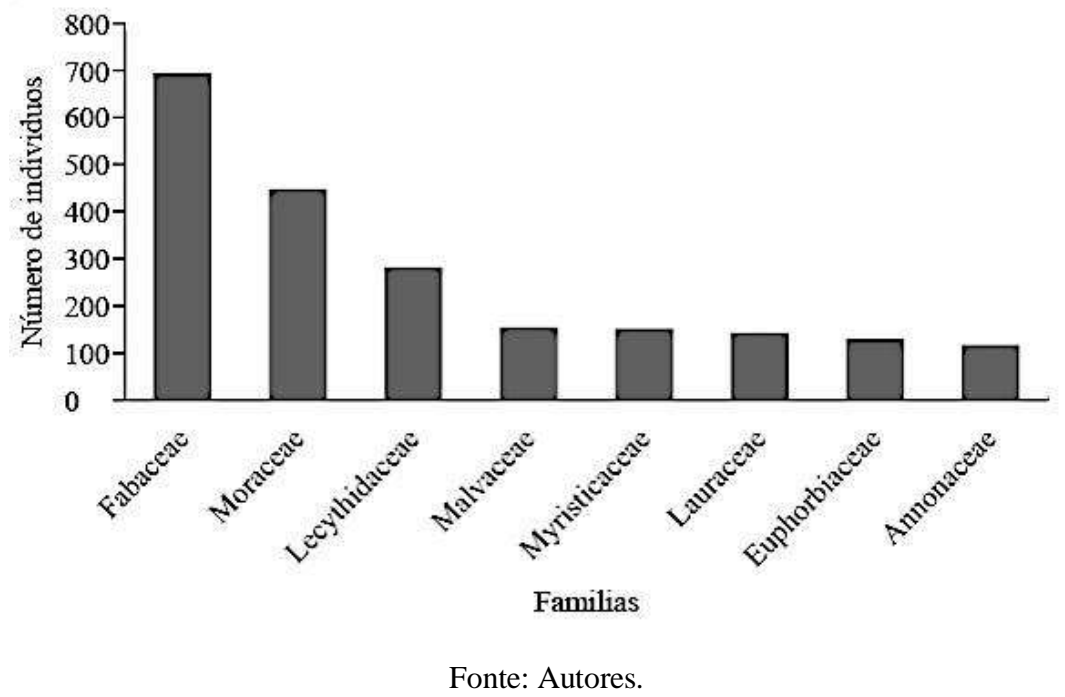

As famílias mais importantes encontradas na UMF III corroboram com os dados de outros trabalhos realizados na região amazônica, que também observaram o predomínio das famílias Fabaceae, Moraceae e Lecythidaceae entre as de maior riqueza de espécies (Bentes-Gama, et al., 2009; Condé \& Tonini, 2013; Silva, et al., 2015).

Essas famílias botânicas além de contribuírem para a biodiversidade local têm espécies de destaque no setor madeireiro e não madeireiro da região, como verificado por Arêdes (2017) que descreveu 29 espécies classificadas para uso madeireiro, conforme a resolução do SFB n 31 de 2016, pertencentes à família Fabaceae, em estudo na FLONA do Jamari. Bueno (2017), que na mesma área, constatou a presença de sete espécies com potencial não madeireiro para essa família. Pinheiro et al. (2021), em área de manejo florestal em Vitória do Jari, no Amapá, verificaram a família Fabaceae como a mais explorada, com 10 espécies, sendo representada neste estudo pelas espécies Vouacapoua americana, Hymenolobium sericeum, Hymenolobium excelsum, Hymenolobium petraeum, Dinizia excelsa, Dipteryx odorata, Vatairea spp., Hymenaea courbaril, Platymiscium spp e Bowdichia nítida.

As espécies Castanheira (Bertholletia excelsa) e Copaíba (Copaifera multijuga), pertencentes às principais famílias botânicas encontradas neste trabalho, são amplamente utilizadas no manejo florestal não madeireiro. Bueno (2017), enfatiza a 
existência de outros grupos de espécies dessas famílias com potencial para o manejo florestal não madeireiro, porém a falta de conhecimento acerca da ecologia, produtos e tecnologia de beneficiamento impedem a sua inclusão no mercado.

Assim como para as espécies com potencial não madeireiro, verifica-se que nos planos operacionais anuais (POA) das unidades de manejo na FLONA do Jamari, se concentram em poucas espécies madeireiras (SFB, 2020). A falta de informações sobre a correta identificação e caracterização tecnológica da madeira são os principais fatores.

O gênero Tachygali, por exemplo, pertencente à família Fabaceae, tem seu manejo dificultado pela falta de identificação a nível de espécie e por conhecimento dos usos da madeira (Brito Junior, 2019). Nas parcelas avaliadas, cinco espécies foram identificadas para este gênero e essa riqueza pode ser maior, visto que algumas árvores foram identificadas até nível de gênero.

Entende-se que a valorização das florestas na Amazônia é uma alternativa para a sua conservação e controle no avanço do desmatamento, principalmente nos estados do Pará, Mato Grosso e Rondônia, que contemplam as maiores taxas de desmatamento acumulado na Amazônia Legal, desencadeando a perda de considerável de biodiversidade nesse Bioma (INPE, 2020).

O Índice de diversidade de Shannon-Weaver foi de 3,87 e o índice de equabilidade de Pielou foi de 0,77. Esses valores foram próximos aos encontrados em outros estudos no bioma Amazônico (Bentes-Gama, et al., 2009; Maués, et al., 2011; Condé \& Tonini, 2013). O índice de Shannon-Wiener para florestas tropicais frequentemente varia de 3,83 a 5,85, valores considerados altos para qualquer tipo de vegetação (Knight, 1975). Diante disso, pode-se verificar que o ambiente florestal estudado possui diversidade florística relativamente alta, mesmo não tendo todos os indivíduos identificados.

Em relação à estrutura fitossociológica, as espécies Protium robustum, Peltogyne paniculata e Pouteria torta foram as espécies com maior Valor de Importância (VI), somaram juntas 15\% do VI total. Os parâmetros que contribuíram para elevar esse índice para as espécies citadas foram principalmente, a densidade e frequência, indicando abundância dessas espécies na área e ampla distribuição, ocorrendo em 100\% das parcelas estudadas (Tabela 3).

Tabela 3. Parâmetros fitossociológicos para as espécies amostradas em parcelas permanentes na Unidade de Manejo Florestal III, FLONA do Jamari - RO.

\begin{tabular}{lccccccc}
\hline \multicolumn{1}{c}{ Espécie } & DA & DR & FA & FR & DoA & DoR & VI \\
\hline Protium robustum & 47,6 & 11,0 & 100,0 & 1,9 & 2,35 & 10,61 & 7,8 \\
NI & 58,1 & 13,5 & 100,0 & 1,9 & 1,14 & 5,15 & 6,8 \\
Peltogyne paniculata & 16,5 & 3,8 & 100,0 & 1,9 & 1,18 & 5,34 & 3,7 \\
Pouteria torta & 19,3 & 4,5 & 94,1 & 1,8 & 1,06 & 4,78 & 3,7 \\
Tachigali spp. & 14,0 & 3,2 & 88,2 & 1,6 & 0,97 & 4,38 & 3,1 \\
Pseudolmedia laevis & 17,8 & 4,1 & 64,7 & 1,2 & 0,57 & 2,58 & 2,6 \\
Beilschmiedia brasiliensis & 15,2 & 3,5 & 100,0 & 1,9 & 0,53 & 2,38 & 2,6 \\
Eschweilera spp. & 14,7 & 3,4 & 82,4 & 1,5 & 0,54 & 2,46 & 2,5 \\
Apeiba echinata & 7,8 & 1,8 & 100,0 & 1,9 & 0,67 & 3,05 & 2,2 \\
Pseudolmedia spp. & 13,6 & 3,2 & 35,3 & 0,7 & 0,54 & 2,45 & 2,1 \\
Inga spp. & 9,3 & 2,2 & 100,0 & 1,9 & 0,39 & 1,75 & 1,9 \\
\hline Sebastiania commersoniana & 11,1 & 2,6 & 76,5 & 1,4 & 0,23 & 1,02 & 1,7 \\
Astronium lecointei & 3,5 & 0,8 & 88,2 & 1,6 & 0,46 & 2,07 & 1,5 \\
Licania heteromorpha & 7,8 & 1,8 & 76,5 & 1,4 & 0,22 & 1,01 & 1,4 \\
Virola michelii & 6,5 & 1,5 & 88,2 & 1,6 & 0,23 & 1,04 & 1,4 \\
Dinizia excelsa & 3,2 & 0,7 & 58,8 & 1,1 & 0,50 & 2,25 & 1,4 \\
Iryanthera grandis & 5,2 & 1,2 & 100,0 & 1,9 & 0,21 & 0,94 & 1,3 \\
Eschweilera coriacea & 8,0 & 1,9 & 35,3 & 0,7 & 0,32 & 1,44 & 1,3 \\
Couratari stellata & 3,2 & 0,7 & 64,7 & 1,2 & 0,44 & 1,98 & 1,3
\end{tabular}




\begin{tabular}{|c|c|c|c|c|c|c|c|}
\hline Tachigali setifera & 4,9 & 1,1 & 70,6 & 1,3 & 0,30 & 1,36 & 1,3 \\
\hline Guarea trunciflora & 7,3 & 1,7 & 70,6 & 1,3 & 0,13 & 0,58 & 1,2 \\
\hline Pseudolmedia sp.2 & 7,2 & 1,7 & 47,1 & 0,9 & 0,22 & 0,99 & 1,2 \\
\hline Esenbeckia leiocarpa & 2,9 & 0,7 & 58,8 & 1,1 & 0,36 & 1,63 & 1,1 \\
\hline Bertholletia excelsa & 1,3 & 0,3 & 52,9 & 1,0 & 0,46 & 2,08 & 1,1 \\
\hline Zygia racemosa & 2,9 & 0,7 & 76,5 & 1,4 & 0,21 & 0,94 & 1,0 \\
\hline Copaifera multijuga & 2,8 & 0,7 & 76,5 & 1,4 & 0,21 & 0,95 & 1,0 \\
\hline Pouteria guianensis & 3,6 & 0,8 & 76,5 & 1,4 & 0,16 & 0,73 & 1,0 \\
\hline Pseudolmedia sp.3 & 6,4 & 1,5 & 29,4 & 0,5 & 0,21 & 0,93 & 1,0 \\
\hline Virola surinamensis & 2,9 & 0,7 & 64,7 & 1,2 & 0,21 & 0,93 & 0,9 \\
\hline Schizolobium parahyba & 2,2 & 0,5 & 58,8 & 1,1 & 0,26 & 1,19 & 0,9 \\
\hline Couepia bracteosa & 2,8 & 0,7 & 58,8 & 1,1 & 0,22 & 1,00 & 0,9 \\
\hline Xylopia sericea & 3,8 & 0,9 & 76,5 & 1,4 & 0,07 & 0,31 & 0,9 \\
\hline Clarisia racemosa & 2,1 & 0,5 & 52,9 & 1,0 & 0,24 & 1,10 & 0,9 \\
\hline Eschweilera ovata & 1,9 & 0,4 & 64,7 & 1,2 & 0,20 & 0,93 & 0,9 \\
\hline Guatteria pteropus & 3,1 & 0,7 & 70,6 & 1,3 & 0,12 & 0,52 & 0,9 \\
\hline Theobroma speciosum & 3,2 & 0,7 & 82,4 & 1,5 & 0,05 & 0,22 & 0,8 \\
\hline Minquartia guianensis & 2,2 & 0,5 & 52,9 & 1,0 & 0,20 & 0,91 & 0,8 \\
\hline Qualea paraensis & 2,1 & 0,5 & 58,8 & 1,1 & 0,17 & 0,78 & 0,8 \\
\hline Huberodendron swietenioides & 2,0 & 0,5 & 35,3 & 0,7 & 0,26 & 1,15 & 0,8 \\
\hline Castilla ulei & 1,3 & 0,3 & 47,1 & 0,9 & 0,21 & 0,96 & 0,7 \\
\hline Hymenaea courbaril & 1,5 & 0,4 & 52,9 & 1,0 & 0,17 & 0,76 & 0,7 \\
\hline Virola theiodora & 3,2 & 0,7 & 47,1 & 0,9 & 0,08 & 0,36 & 0,7 \\
\hline Guatteria spp. & 2,2 & 0,5 & 58,8 & 1,1 & 0,06 & 0,27 & 0,6 \\
\hline Swartzia sp. & 1,9 & 0,4 & 58,8 & 1,1 & 0,07 & 0,30 & 0,6 \\
\hline Hymenolobium sp. & 2,4 & 0,5 & 47,1 & 0,9 & 0,07 & 0,34 & 0,6 \\
\hline Theobroma subincanum & 1,5 & 0,4 & 52,9 & 1,0 & 0,09 & 0,39 & 0,6 \\
\hline Brosimum rubescens & 1,6 & 0,4 & 35,3 & 0,7 & 0,15 & 0,67 & 0,6 \\
\hline Tabebuia incana & 1,2 & 0,3 & 41,2 & 0,8 & 0,15 & 0,66 & 0,6 \\
\hline Tachigali subvelutina & 2,4 & 0,5 & 47,1 & 0,9 & 0,05 & 0,24 & 0,6 \\
\hline Ormosia sp. & 1,6 & 0,4 & 47,1 & 0,9 & 0,08 & 0,38 & 0,5 \\
\hline Dipteryx odorata & 1,2 & 0,3 & 47,1 & 0,9 & 0,09 & 0,40 & 0,5 \\
\hline Tachigali chrysophylla & 1,4 & 0,3 & 41,2 & 0,8 & 0,10 & 0,45 & 0,5 \\
\hline Lecythis idatimon & 2,7 & 0,6 & 23,5 & 0,4 & 0,11 & 0,47 & 0,5 \\
\hline Trattinnickia rhoifolia & 1,8 & 0,4 & 47,1 & 0,9 & 0,05 & 0,22 & 0,5 \\
\hline Onychopetalum amazonicum & 1,8 & 0,4 & 35,3 & 0,7 & 0,08 & 0,34 & 0,5 \\
\hline Vatairea fusca & 1,2 & 0,3 & 41,2 & 0,8 & 0,08 & 0,34 & 0,5 \\
\hline Brosimum acutifolium & 1,1 & 0,2 & 35,3 & 0,7 & 0,11 & 0,48 & 0,5 \\
\hline Rhodothyrsus macrophyllus & 3,1 & 0,7 & 23,5 & 0,4 & 0,05 & 0,22 & 0,5 \\
\hline Protium heptaphyllum & 1,2 & 0,3 & 41,2 & 0,8 & 0,07 & 0,32 & 0,5 \\
\hline Parkia multijuga & 0,9 & 0,2 & 23,5 & 0,4 & 0,16 & 0,70 & 0,5 \\
\hline Hymenolobium heterocarpum & 0,7 & 0,2 & 35,3 & 0,7 & 0,11 & 0,52 & 0,4 \\
\hline Cecropia sp. & 1,4 & 0,3 & 41,2 & 0,8 & 0,05 & 0,24 & 0,4 \\
\hline Vitex montevidensis & 1,1 & 0,2 & 47,1 & 0,9 & 0,03 & 0,15 & 0,4 \\
\hline Dialium guianense & 0,8 & 0,2 & 35,3 & 0,7 & 0,09 & 0,41 & 0,4 \\
\hline Cariniana micrantha & 0,2 & 0,1 & 11,8 & 0,2 & 0,19 & 0,87 & 0,4 \\
\hline Sterculia chicha & 0,9 & 0,2 & 35,3 & 0,7 & 0,06 & 0,27 & 0,4 \\
\hline Buchenavia parvifolia & 0,7 & 0,2 & 35,3 & 0,7 & 0,07 & 0,32 & 0,4 \\
\hline Aspidosperma spp. & 1,1 & 0,2 & 41,2 & 0,8 & 0,02 & 0,10 & 0,4 \\
\hline Apuleia leiocarpa & 0,6 & 0,1 & 23,5 & 0,4 & 0,11 & 0,50 & 0,4 \\
\hline Aspidosperma sp.1 & 0,8 & 0,2 & 35,3 & 0,7 & 0,05 & 0,22 & 0,4 \\
\hline Pseudobombax grandiflorum & 0,8 & 0,2 & 35,3 & 0,7 & 0,05 & 0,21 & 0,4 \\
\hline
\end{tabular}




\begin{tabular}{|c|c|c|c|c|c|c|c|}
\hline Terminalia amazonica & 0,5 & 0,1 & 23,5 & 0,4 & 0,11 & 0,51 & 0,4 \\
\hline Brosimum paraense & 0,8 & 0,2 & 29,4 & 0,5 & 0,07 & 0,30 & 0,3 \\
\hline Aegiphila integrifolia & 0,7 & 0,2 & 29,4 & 0,5 & 0,07 & 0,31 & 0,3 \\
\hline Couma utilis & 0,8 & 0,2 & 41,2 & 0,8 & 0,01 & 0,06 & 0,3 \\
\hline Sterculia spp. & 1,4 & 0,3 & 29,4 & 0,5 & 0,03 & 0,14 & 0,3 \\
\hline Erisma cf. bicolor & 1,1 & 0,2 & 29,4 & 0,5 & 0,05 & 0,22 & 0,3 \\
\hline Cariniana integrifolia & 0,8 & 0,2 & 23,5 & 0,4 & 0,09 & 0,38 & 0,3 \\
\hline Parkia sp. & 0,7 & 0,2 & 35,3 & 0,7 & 0,04 & 0,18 & 0,3 \\
\hline Guatteria discolor & 1,1 & 0,2 & 35,3 & 0,7 & 0,02 & 0,07 & 0,3 \\
\hline Hevea brasiliensis & 0,8 & 0,2 & 23,5 & 0,4 & 0,08 & 0,34 & 0,3 \\
\hline Parkia nitida & 0,6 & 0,1 & 29,4 & 0,5 & 0,06 & 0,29 & 0,3 \\
\hline Cariniana sp. & 0,4 & 0,1 & 17,6 & 0,3 & 0,12 & 0,55 & 0,3 \\
\hline Pourouma bicolor & 0,8 & 0,2 & 29,4 & 0,5 & 0,05 & 0,21 & 0,3 \\
\hline Cordia goeldiana & 0,7 & 0,2 & 23,5 & 0,4 & 0,07 & 0,34 & 0,3 \\
\hline Copaifera sp. & 0,6 & 0,1 & 23,5 & 0,4 & 0,07 & 0,33 & 0,3 \\
\hline Mimosa caesalpinïfolia & 0,9 & 0,2 & 17,6 & 0,3 & 0,07 & 0,34 & 0,3 \\
\hline Goupia glabra & 0,5 & 0,1 & 23,5 & 0,4 & 0,07 & 0,31 & 0,3 \\
\hline Stryphnodendron pulcherrimum & 0,8 & 0,2 & 23,5 & 0,4 & 0,05 & 0,23 & 0,3 \\
\hline Bowdichia nitida & 0,6 & 0,1 & 29,4 & 0,5 & 0,03 & 0,13 & 0,3 \\
\hline Endopleura uchi & 0,7 & 0,2 & 23,5 & 0,4 & 0,05 & 0,21 & 0,3 \\
\hline Swartzia acuminata & 0,5 & 0,1 & 23,5 & 0,4 & 0,06 & 0,27 & 0,3 \\
\hline Bellucia grossularioides & 0,7 & 0,2 & 29,4 & 0,5 & 0,02 & 0,09 & 0,3 \\
\hline Bauhinia sp. & 1,4 & 0,3 & 11,8 & 0,2 & 0,05 & 0,22 & 0,3 \\
\hline Simarouba amara & 0,7 & 0,2 & 23,5 & 0,4 & 0,03 & 0,15 & 0,3 \\
\hline Ocotea nigrescens & 0,8 & 0,2 & 23,5 & 0,4 & 0,02 & 0,10 & 0,2 \\
\hline Andira trifoliolata & 0,6 & 0,1 & 17,6 & 0,3 & 0,05 & 0,25 & 0,2 \\
\hline Geissospermum laeve & 0,5 & 0,1 & 23,5 & 0,4 & 0,03 & 0,15 & 0,2 \\
\hline Ocotea sp. & 0,5 & 0,1 & 23,5 & 0,4 & 0,03 & 0,14 & 0,2 \\
\hline Buchenavia sp. & 0,6 & 0,1 & 23,5 & 0,4 & 0,02 & 0,10 & 0,2 \\
\hline Anemopaegma spp. & 0,6 & 0,1 & 17,6 & 0,3 & 0,04 & 0,19 & 0,2 \\
\hline Byrsonima crispa & 0,6 & 0,1 & 17,6 & 0,3 & 0,04 & 0,16 & 0,2 \\
\hline Caryocar pallidum & 0,4 & 0,1 & 17,6 & 0,3 & 0,05 & 0,21 & 0,2 \\
\hline Tachigali poeppigiana & 0,6 & 0,1 & 23,5 & 0,4 & 0,01 & 0,03 & 0,2 \\
\hline Enterolobium schomburgkii & 0,4 & 0,1 & 17,6 & 0,3 & 0,04 & 0,20 & 0,2 \\
\hline Duguetia sp. & 0,6 & 0,1 & 17,6 & 0,3 & 0,03 & 0,14 & 0,2 \\
\hline Zanthoxylum rhoifolium & 0,5 & 0,1 & 23,5 & 0,4 & 0,01 & 0,03 & 0,2 \\
\hline Calycophyllum spruceanum & 0,6 & 0,1 & 17,6 & 0,3 & 0,02 & 0,10 & 0,2 \\
\hline Xylopia nítida & 1,1 & 0,2 & 11,8 & 0,2 & 0,02 & 0,10 & 0,2 \\
\hline Mezilaurus itauba & 0,2 & 0,1 & 11,8 & 0,2 & 0,06 & 0,27 & 0,2 \\
\hline Manilkara huberi & 0,4 & 0,1 & 11,8 & 0,2 & 0,05 & 0,24 & 0,2 \\
\hline Sterculia excelsa & 0,5 & 0,1 & 17,6 & 0,3 & 0,02 & 0,10 & 0,2 \\
\hline Laetia procera & 0,4 & 0,1 & 17,6 & 0,3 & 0,03 & 0,12 & 0,2 \\
\hline Caryocar villosum. & 0,2 & 0,1 & 11,8 & 0,2 & 0,05 & 0,24 & 0,2 \\
\hline Pseudolmedia sp. & 0,5 & 0,1 & 17,6 & 0,3 & 0,01 & 0,03 & 0,2 \\
\hline Anemopaegma sp. & 0,1 & 0,0 & 5,9 & 0,1 & 0,07 & 0,33 & 0,2 \\
\hline Erisma fuscum & 0,6 & 0,1 & 11,8 & 0,2 & 0,02 & 0,11 & 0,2 \\
\hline Cordiera concolor & 0,4 & 0,1 & 17,6 & 0,3 & 0,01 & 0,05 & 0,2 \\
\hline Sapium marmieri & 0,4 & 0,1 & 11,8 & 0,2 & 0,03 & 0,14 & 0,1 \\
\hline Cedrela fissilis & 0,2 & 0,1 & 11,8 & 0,2 & 0,03 & 0,14 & 0,1 \\
\hline Anemopaegma sp.1 & 0,2 & 0,1 & 11,8 & 0,2 & 0,03 & 0,12 & 0,1 \\
\hline Anacardium parvifolium & 0,2 & 0,1 & 11,8 & 0,2 & 0,02 & 0,08 & 0,1 \\
\hline Parkia pendula & 0,4 & 0,1 & 11,8 & 0,2 & 0,01 & 0,04 & 0,1 \\
\hline
\end{tabular}




\begin{tabular}{|c|c|c|c|c|c|c|c|}
\hline Aspidosperma polyneuron & 0,2 & 0,1 & 11,8 & 0,2 & 0,01 & 0,07 & 0,1 \\
\hline Platonia insignis & 0,4 & 0,1 & 11,8 & 0,2 & 0,01 & 0,04 & 0,1 \\
\hline Anadenanthera colubrina & 0,2 & 0,1 & 11,8 & 0,2 & 0,01 & 0,06 & 0,1 \\
\hline Bixa arbórea & 0,2 & 0,1 & 11,8 & 0,2 & 0,01 & 0,05 & 0,1 \\
\hline Jacaranda copaia & 0,2 & 0,1 & 11,8 & 0,2 & 0,01 & 0,03 & 0,1 \\
\hline Ruizodendron sp. & 0,2 & 0,1 & 11,8 & 0,2 & 0,00 & 0,02 & 0,1 \\
\hline Vismia guianensis & 0,2 & 0,1 & 11,8 & 0,2 & 0,00 & 0,01 & 0,1 \\
\hline Buchenavia Eichler & 0,1 & 0,03 & 5,9 & 0,1 & 0,03 & 0,13 & 0,1 \\
\hline Ficus sp. & 0,1 & 0,03 & 5,9 & 0,1 & 0,02 & 0,11 & 0,1 \\
\hline Bowdichia sp. & 0,1 & 0,03 & 5,9 & 0,1 & 0,02 & 0,07 & 0,1 \\
\hline Bagassa guianensis & 0,1 & 0,03 & 5,9 & 0,1 & 0,01 & 0,05 & 0,1 \\
\hline Peltogyne venosa & 0,1 & 0,03 & 5,9 & 0,1 & 0,01 & 0,03 & 0,1 \\
\hline Pouteria sp. & 0,1 & 0,03 & 5,9 & 0,1 & 0,01 & 0,03 & 0,1 \\
\hline Anacardium sp. & 0,1 & 0,03 & 5,9 & 0,1 & 0,01 & 0,03 & 0,1 \\
\hline Platymiscium trinitatis & 0,1 & 0,03 & 5,9 & 0,1 & 0,004 & 0,019 & 0,1 \\
\hline Himatanthus revolutus & 0,1 & 0,03 & 5,9 & 0,1 & 0,004 & 0,019 & 0,1 \\
\hline Diplotropis rodriguesii & 0,1 & 0,03 & 5,9 & 0,1 & 0,004 & 0,018 & 0,1 \\
\hline Peltogyne sp. & 0,1 & 0,03 & 5,9 & 0,1 & 0,004 & 0,017 & 0,1 \\
\hline Syzygium spp. & 0,1 & 0,03 & 5,9 & 0,1 & 0,003 & 0,016 & 0,1 \\
\hline Coccoloba sp. & 0,1 & 0,03 & 5,9 & 0,1 & 0,003 & 0,013 & 0,05 \\
\hline Ocotea fragrantíssima & 0,1 & 0,03 & 5,9 & 0,1 & 0,003 & 0,013 & 0,05 \\
\hline Protium sagotianum & 0,1 & 0,03 & 5,9 & 0,1 & 0,003 & 0,012 & 0,05 \\
\hline Dipteryx polyphylla & 0,1 & 0,03 & 5,9 & 0,1 & 0,002 & 0,009 & 0,05 \\
\hline Enterolobium maximum & 0,1 & 0,03 & 5,9 & 0,1 & 0,002 & 0,009 & 0,05 \\
\hline Vochysia sp. & 0,1 & 0,03 & 5,9 & 0,1 & 0,001 & 0,006 & 0,05 \\
\hline Poecilanthe parviflora & 0,1 & 0,03 & 5,9 & 0,1 & 0,001 & 0,006 & 0,05 \\
\hline Pseudomedia sp.1 & 0,1 & 0,03 & 5,9 & 0,1 & 0,001 & 0,005 & 0,05 \\
\hline Qualea spp. & 0,1 & 0,03 & 5,9 & 0,1 & 0,001 & 0,004 & 0,05 \\
\hline
\end{tabular}

$\mathrm{DA}=$ Densidade Absoluta $\left(\right.$ ind ha $\left.^{-1}\right) ; \mathrm{DR}=$ Densidade Relativa $(\%) ; \mathrm{FA}=$ Frequência Absoluta $(\%) ; \mathrm{FR}=$ Frequência Relativa $(\%) ;$ DoA = Dominância Absoluta $\left(\mathrm{m}^{2} \mathrm{ha}^{-1}\right)$; DoR = Dominância Relativa (\%); VI = Valor de Importância (\%). Fonte: Autores.

Nota-se que as 10 espécies mais importantes listadas acima, representam 40,7\% do total de indivíduos amostrados, evidenciando a predominância na área estudada. Ressalta-se que três gêneros (Tachigali spp., Eschweilera spp. e Inga spp.) estão adicionados a esse valor, pois não foi possível a sua diferenciação em nível de epíteto específico e a coleta de material botânico desses indivíduos não foi possível em função da altura das árvores.

No trabalho de Arêdes (2017), foram listadas três espécies do gênero Eschweilera: Eschweilera coreace, Eschweilera odorata e Eschweilera pseudo decolorans, sendo a última, a que teve maior densidade de árvores.

Cysneros et al. (2018), citam que um erro comum nos inventários florestais na Amazônia decorre da variação dos nomes populares, que apresentam peculiaridades regionais e podem ser atribuídos a diversas espécies simultaneamente. Neste mesmo trabalho, as espécies do gênero Eschweilera e Tachigali foram observadas dentre os táxons com identificação incompleta ou nomes comuns atribuídos a mais de uma espécie, respectivamente.

O predomínio de alguns grupos de espécies na estrutura da floresta também foi verificado em outros estudos na Amazônia. Lima et al. (2012), verificaram que 57,5\% dos indivíduos amostrados em estudo de Floresta Ombrófila Densa no Amazonas pertenciam às 10 espécies com maior VI. Os mesmos autores citaram ainda, os gêneros Pouteria, Eschweilera e Inga com maior valor de importância. Bentes-Gama et al. (2009) e Jacobsen et al. (2015), também destacaram a importância dos gêneros Eschweilera e Protium na estrutura da floresta em estudos em Rondônia. As espécies com maior valor de importância expressam as características das tipologias florestais e servem como espécies indicadoras desses locais, pois apresentam melhor adequação aos ambientes da floresta (Moro \& Martins, 2011). 
Outro resultado que merece destaque na estrutura das espécies identificadas nas parcelas estudadas refere-se ao quantitativo de espécies raras. Do total de espécies observadas, 55\% (84 espécies) apresentaram densidade absoluta menor que 1 ind ha ${ }^{-1}$, configurando caráter mais restrito na área estudada. As espécies raras, em ambientes antropizados, podem tornar-se mais vulneráveis à extinção porque, em geral, são especializadas a um conjunto restrito de fatores ambientais ou têm baixa capacidade de dispersão (Oliveira \& Amaral, 2005).

Além das espécies raras, observou-se nos pontos amostrados a presença de espécies listadas como ameaçadas de extinção, conforme Livro Vermelho de Espécies Ameaçadas de Extinção no Brasil, Portaria nº 443, de 17 de dezembro de 2014. Dentre essas espécies, cita-se Apuleia leiocarpa (garapeira), Bertholletia excelsa (Castanheira), Cedrela fissilis (Cedro rosa), Mezilaurus itauba (itaúba) e Platymiscium trinitatis (macacaúba) classificadas como espécies vulneráveis, ou seja, enfrentam um risco de extinção elevado na natureza (MMA, 2014). Com exceção de castanheira, todas as outras espécies apresentaram densidade absoluta abaixo de 1 ind $\mathrm{ha}^{-1}$, indicando a necessidade de controle dessas populações diante das alterações causadas pelo uso da floresta.

De forma geral, verifica-se alta riqueza de espécies, porém a maioria apresenta populações pouco estruturadas na floresta, sendo importante assegurar a conservação desses grupos, principalmente em unidades de conservação (UC's).

As UC's são áreas instituídas pelo poder público e asseguradas por legislação própria, especificada no Sistema Nacional de Unidades de Conservação (SNUC), como locais que visam contribuir para a manutenção da diversidade biológica e dos recursos genéticos e a proteção das espécies ameaçadas de extinção (Brasil, 2000). Em unidades de uso sustentável, como a FLONA do Jamari, é importante que se faça o monitoramento dessas populações, a fim de assegurar a manutenção e conservação tanto de espécies raras, como aquelas de ameaçadas de extinção, principalmente as que fazem parte dos planos de manejo florestal, como cedro rosa, itaúba, entre outras (Souza \& Sccoti, 2020).

A maior parte dos estoques em densidade de plantas, área basal e volume da população estudada encontram-se nas classes de DAP abaixo de $50 \mathrm{~cm}$ (Tabela 4), considerado nos planos de manejo florestal como estoques remanescentes da floresta (Brasil, 2009).

As árvores com DAP $\leq 50 \mathrm{~cm}$ representam $95 \%$ da densidade total e aproximadamente, $66 \%$ e $84 \%$ dos valores de área basal total e volume total. Ressalta-se que esse valor corresponde a todas as espécies amostradas e nos planos de manejo a regulação da produção é feita com base nos estoques das espécies comerciais, ou que constam na lista de espécies manejadas (Souza \& Soares, 2013). 
Tabela 4. Estrutura paramétrica por classe de DAP observada para árvores com DAP $\geq 10 \mathrm{~cm}$ em unidade de manejo florestal na FLONA do Jamari, RO.

\begin{tabular}{cccc}
\hline Classes de DAP $(\mathbf{c m})$ & DA $\left(\mathbf{i n d} \mathbf{h a}^{\mathbf{- 1}}\right)$ & $\mathbf{G}\left(\mathbf{m}^{\mathbf{2}} \mathbf{h a}^{-\mathbf{1}}\right)$ & $\mathbf{V}\left(\mathbf{m}^{\mathbf{3}} \mathbf{h}^{\mathbf{- 1}}\right)$ \\
\hline $10-20$ & 271,76 & 4,38 & 285,75 \\
$20-30$ & 82,00 & 3,76 & 108,61 \\
$30-40$ & 38,59 & 3,61 & 69,13 \\
$40-50$ & 18,35 & 2,88 & 44,63 \\
$50-60$ & 10,47 & 2,46 & 33,81 \\
$60-70$ & 4,94 & 1,59 & 20,38 \\
$70-80$ & 2,82 & 1,21 & 14,78 \\
$80-90$ & 1,41 & 0,78 & 9,30 \\
$90-100$ & 0,71 & 0,51 & 5,94 \\
$100-110$ & 0,12 & 0,10 & 1,18 \\
$110-120$ & 0,24 & 0,24 & 2,66 \\
$130-140$ & 0,12 & 0,17 & 1,90 \\
$140-150$ & 0,12 & 0,19 & 2,10 \\
$160-170$ & 0,12 & 0,24 & 2,69 \\
\hline Total geral & $\mathbf{4 3 1 , 7 6}$ & $\mathbf{2 2 , 1 2}$ & $\mathbf{6 0 2 , 8 5}$
\end{tabular}

$\mathrm{DA}=$ densidade absoluta; $\mathrm{G}=$ área basal; $\mathrm{V}=$ volume. Fonte: Autores.

Algumas espécies merecem destaque em termos de estoques (Tabela 5). Pouteria torta, Peltogyne paniculata, Eschweilera coriacea, Beilschmiedia brasiliensis, Eschweilera spp., por exemplo, são espécies com valor madeireiro na região, muito utilizadas nos planos de manejo florestal. É importante observar estoques tanto nas maiores classes de tamanho, como nos estoques remanescentes, pois esse padrão estrutural indica maior estabilidade de se manterem na floresta quando utilizadas de forma sustentável em planos de manejo florestal.

Tabela 5. Espécies com maiores valores de densidade, área basal e volume, observadas em unidade de manejo florestal na FLONA do Jamari, RO.

\begin{tabular}{|c|c|c|c|}
\hline Espécie & DA (ind ha ${ }^{-1}$ ) & $\mathbf{G}\left(\mathbf{m}^{2} \mathbf{h a}^{-1}\right)$ & $V\left(\mathbf{m}^{3} \mathbf{h a}^{-1}\right)$ \\
\hline Protium robustum & 47,65 & 2,35 & 65,32 \\
\hline Pouteria torta & 19,29 & 1,06 & 27,52 \\
\hline Pseudolmedia laevis & 17,76 & 0,57 & 21,34 \\
\hline Peltogyne paniculata & 16,47 & 1,18 & 26,33 \\
\hline Beilschmiedia brasiliensis & 15,18 & 0,53 & 18,64 \\
\hline Eschweilera spp. & 14,71 & 0,54 & 18,43 \\
\hline Tachigali spp. & 14,00 & 0,97 & 22,03 \\
\hline Pseudolmedia spp. & 13,65 & 0,54 & 17,41 \\
\hline Sebastiania commersoniana & 11,06 & 0,23 & 12,07 \\
\hline Inga spp. & 9,29 & 0,39 & 12,06 \\
\hline Eschweilera coriacea & 8,00 & 0,32 & 10,22 \\
\hline Apeiba echinata & 7,76 & 0,67 & 13,54 \\
\hline
\end{tabular}

$\mathrm{DA}=$ densidade absoluta; $\mathrm{G}$ = área basal; $\mathrm{V}$ = volume. Fonte: Autores. 
Outra espécie de grande procura e com considerável valor de mercado é o Ipê (Handroanthus incanus). Na área estudada, essa espécie apresentou, em média, densidade de 1,2 ind. ha ${ }^{-1}$ e área basal de $0,14 \mathrm{~m}^{2}$ ha $^{-1}$ e volume de $2,49 \mathrm{~m}^{3} \mathrm{ha}^{-1}$. Recentemente, os sites de notícias reportaram uma nova medida do Governo Federal brasileiro acerca da retirada do Ipê da lista de espécies ameaçadas da convenção sobre o comércio internacional de espécies da fauna e da flora selvagem (G1, 2020). A convenção é um acordo internacional assinado pelo Brasil em 1973, nesta lista encontram-se também as espécies mogno (Swietenia macrophylla King) e pau-brasil (Caesalpinia echinata Lam.).

Neste caso, a madeira de ipê pode ser comercializada no mercado internacional sem nenhum tipo de rigor ou fiscalização, o que pode facilitar o comércio ilegal dessa espécie. Assim é importante que ao tomar decisões associadas a essas questões, os órgãos de gestão e controle fiscal atentem-se para trabalhos científicos que expressam o comportamento da espécie, avaliando a eficiência das leis brasileiras no controle aos crimes relacionados à exploração ilegal de madeira e a conservação dos recursos biológicos do país.

\section{Conclusão}

O trecho de floresta estudado na Unidade de manejo florestal III da FLONA do Jamari apresentou composição e estrutura semelhante às florestas conservadas na Amazônia.

A maior parte da composição florística foi representada por poucas famílias botânicas e por um alto número de espécies raras, sendo importante o desenvolvimento de programas de monitoramento para essas espécies em áreas manejadas.

A identificação das espécies florestais representou um problema no inventário florestal, sendo importante investir em pesquisas voltadas para essa área.

Protium robustum, Peltogyne paniculata, Pouteria torta, Tachigali spp., Eschweilera spp. e Inga spp. representam o maior percentual de valor de importância e estoques na floresta.

O maior estoque em densidade de árvores, área basal e volume se concentram nas árvores com DAP abaixo de $50 \mathrm{~cm}$.

A Floresta Nacional do Jamari é uma unidade de conservação de grande importância ecológica, cultural e social para o estado de Rondônia. Contém grande biodiversidade do Bioma Amazônico e deve ser protegida por Leis e políticas federais e estaduais que assegurem a sua conservação.

\section{Agradecimentos}

Ao CNPq por concessão de recurso por meio do Edital 14/2012.

Ao Instituto Chico Mendes de Conservação da Biodiversidade e ao Serviço Florestal Brasileiro pela disponibilidade da área de estudo.

A empresa Amata S/A, por apoio financeiro e logístico.

\section{Referências}

Alarcón, J. G. S., \& Peixoto, A. L. (2007). Florística e fitossociologia de um trecho de um hectare de floresta de terra firme, em Caracaraí, Roraima, Brasil. Boletim do Museu Paraense Emilio Goeldi Ciências Naturais, 2(2), 33-60. http://scielo.iec.gov.br/scielo.php?script=sci_arttext\&pid=S198181142007000200004

Alvares, C. A, Stape, J. L., Sentelhas, P. C., Gonçalves, L. M., \& Sparovek, G. (2013). Köppen's climate classification map for Brazil. Meteorologische Zeitschrift, 22(6), 711-728. 10.1127/0941-2948/2013/0507

AMATA. (2007). Plano de manejo florestal sustentável categoria de PMFS: pleno. AMATA S.A..

AMATA. (2014). Plano operacional anual 05 UMF III. AMATA S.A.

Arêdes, L. C. (2017). Potencial madeireiro em Unidades de Conservação de uso sustentável sob regime de Concessão: O caso da FLONA do Jamari-RO. Universidade Federal de Rondônia. http://www.pi.unir.br/uploads/37388400/arquivos/Let_cia_Cordeiro_Ar_des_409043802.pdf 
Bentes-Gama, M. M., Leal, G. S., Barros, J. D. O., Lopes, R. H., Zamora López, G. F., \& Silveira, J. C. (2009). Características da estrutura de uma floresta de terra firme em Porto Velho, Rondônia. Embrapa Rondônia.

Brasil. (2000). Lei no 9.985 de 18 de julho de 2000. Regulamenta o art. 225, § 1o, incisos I, II, III e VII da Constituição Federal, institui o Sistema Nacional de Unidades de Conservação da Natureza e dá outras providências. http://www.planalto.gov.br/ccivil_03/leis/L9985.htm.

Brasil. (2006). Lei $\mathrm{n}^{\circ} 11.284$ de 2 de março de 2006. Dispõe sobre a gestão de florestas públicas para a produção sustentável; institui, na estrutura do Ministério do Meio Ambiente, o Serviço Florestal Brasileiro - SFB; cria o Fundo Nacional de Desenvolvimento Florestal - FNDF; altera as Leis nos 10.683 , de 28 de maio de 2003, 5.868, de 12 de dezembro de 1972, 9.605, de 12 de fevereiro de 1998, 4.771, de 15 de setembro de 1965, 6.938, de 31 de agosto de 1981, e 6.015, de 31 de dezembro de 1973; e dá outras providências. http://www.planalto.gov.br/ccivil_03/_Ato2004-2006/2006/Lei/L11284.htm

Brasil. (2009). Resolução n 406, de 02 de fevereiro de 2009. Estabelece parâmetros técnicos a serem adotados na elaboração, apresentação, avaliação técnica e execução de Plano de Manejo Florestal Sustentável-PMFS com fins madeireiros, para florestas nativas e suas formas de sucessão no bioma Amazônia. https://progredir.institutoprosaber.com.br/acesso-ava/amhvdmVuMg==

Brito Junior, J. F. (2018). Dendrologia de espécies arbóreas de uso comercial na Floresta Nacional do Jamari. Universidade Federal de Rondônia.

Brito Junior, J. F. (2019). Identificação de espécies do gênero Tachigali Aubl., na Floresta Nacional do Jamari, Rondônia. Universidade Federal de Rondônia.

Brito Junior, J. F., Sccoti, M. S. V., Biazatti, S. C., \& Pereira, B. L. C. (2021). Anatomical characterization of wood for identification of the Tachigali Aubl. Species. Revista Ibero-americana de Ciências Ambientais, 12(3), 1-14. https://www.sustenere.co/index.php/rica/article/view/5103

Bueno, K, N. (2017). Potencial exploratório de produtos florestais não madeireiros na FLONA do Jamari-RO. Universidade Federal de Rondônia. http://www.engenhariaflorestal.unir.br/uploads/37388400/arquivos/Karem_Natany_Toledo_Bueno_775624741.pdf

Chase, M. W., Christenhusz, M. J. M., Fay, M. F., Byng, J. W., Judd, W. S., Soltis, D. E., Mabberley, D. J., Sennikov, A. N., Soltis, P. S., \& Stevens, P. F. (2016). An update of the Angiosperm Phylogeny Group classification for the orders and families of flowering plants. Botanical Journal of the Linnean Society, 181(1), 1-20. 10.1111/boj.12385

Condé, T. M., \& Tonini, H. (2013). Fitossociologia de uma floresta ombrófila densa na Amazônia Setentrional, Roraima, Brasil. Acta Amazônica, 43(3), 247259. $10.1590 / \mathrm{S} 0044-59672013000300002$

Cysneiros, V. C., Júnior, J. O. M., Lanza, T. R., Moraes, J. C. R., \& Samor, O. J. M. (2018). Espécies madeireiras da Amazônia: riqueza, nomes populares e suas peculiaridades. Pesquisa Florestal Brasileira, 38, 1-14. 10.4336/2018.pfb.38e201801567

Felfili, J. M., \& Venturoli, F. (2000). Tópicos em análise da vegetação. Universidade de Brasília.

Forzza, R., Baumgratz, J., Bicudo, C., Canhos, D., Carvalho Jr, A. A., Nadruz, M., Costa, A., Costa, D., Hopkins, M., Leitman, P., Lohmann, L. G., Nic Lughadha, E. M., Maia, L., Martinelli, G., Menezes, M., Morim, M., Peixoto, A. L., Pirani, J. R., Prado, Queiroz, L. P., Souza, S., Castro, V. S., Stehmann, J. R., Sylvestre, L. S., Walter, B.M.T., \& Zappi, D.C. (2012). New Brazilian Floristic List Highlights Conservation Challenges. BioScience. 62, 39-45. 10.1525/bio.2012.62.1.8

G1. (2020). Governo retira ipê de lista internacional de proteção de espécies ameaçadas. https://g1.globo.com/natureza/noticia/2020/11/26/governo-retiraipe-de-lista-internacional-de-protecao-de-especies-ameacadas.ghtml

IBGE - Instituto Brasileiro de Geografia e Estatística. (1992). Manual técnico da vegetação brasileira. IBGE. https://biblioteca.ib ge.gov.br/visualizacao/monografias/GEBIS\%20-\%20RJ/ManuaisdeGeociencias/Manual\%20Tecnico\%20 da\%20Vegetacao\%20B rasileira\%20n.1.pdf

INPE - Instituto Nacional de Pesquisas Espaciais. Monitoramento do desmatamento da floresta amazônica brasileira por satélite. (2020). http://www.obt.inpe.br/OBT/assuntos/programas/amazonia/prodes

Jacobsen, R. H. F., Sccoti, M. S. V., Barboza, E., Bento, A. R., \& Silva, R. P. (2015). Grupos florísticos em remanescente de Floresta Ombrófila Aberta Submontana. Revista Brasileira de Ciências da Amazônia, 4, 41-52. https://www.periodicos.unir.br/index.php/rolimdemoura/article/download/1748/1657

Jacobsen, R. H. F., Sccoti, M. S. V., Fagundes, S. T. S., Brito Junior, J. F., \& Biazatti, S. C. (2020). Impacts on vegetation after selective cutting in forest concession area in the South Western Brazilian Amazon. Floresta, 50(4),1778-1787. 10.5380/rf.v50 i4. 65680

Lima, R. B. A., Silva, J. A. A., Marangon, L. C, Ferreira, R. L. C., \& Silva, R. K. S. (2012). Fitossociologia de um trecho de floresta ombrófila densa na Reserva de Desenvolvimento Sustentável Uacari, Carauari, Amazonas. Scientia Plena, 8(1), 1-13.

Knight, D. H. (1975). A phytosociological analysis of species-rich tropical forest on Barro Colorado Island, Panama. Ecological monographs, 45(3), $259-284$.

Marchiori, J. N. C. (2007). Dendrologia das Angiospermas: leguminosas. (2a ed.), Editora UFSM.

Martins, F. R. (1991). Estrutura de uma floresta mesófila. Editora UNICAMP.

Matos, F. D. D. A., \& Amaral, I. L. D. (1999). Análise ecológica de um hectare em floresta Ombrófila densa de terra-firme, estrada da Várzea, Amazonas, Brasil. Acta Amazonica, 29(3), 365-365. 10.1590/1809-43921999293379

Maués, B. A. R., Jardim, M. A. G., Batista, F. D. J., Medeiros, T. D. S., \& Quaresma, A. D. C. (2011). Composição florística e estrutura do estrato inferior da floresta de várzea na área de proteção ambiental Ilha do Combu, município de Belém, Estado do Pará. Revista Árvore, 35(3), 669-677. 10.1590/S010067622011000400011

Mueller-Dombois, D., \& Ellenberg, H. (1974). Aims and methods of https://www.researchgate.net/publication/259466952_Aims_and_methods_of_vegetation_ecology

vegetation ecology. John Wiley \& Sons. 
MMA - Ministério do Meio Ambiente. (2018). Cobertura de unidades de conservação por Bioma e por Tipo (Proteção Integral e Uso Sustentável). www.mma.gov.br/esruturas/219/_arquivos/texto_indicadores_uc_01fev11_219.pdf

MMA - Ministério do Meio Ambiente. (2021). Fauna e Flora. https://www.gov.br/mma/pt-br/assuntos/biodiversidade/fauna-e-flora

MMA - Ministério do Meio Ambiente. (2014). Portaria $n^{\circ} 443$, de 17 de dezembro de 2014. Atualização da lista de espécies ameaçadas de extinção da flora brasileira.http://cncflora.jbrj.gov.br/portal/static/pdf/portaria_mma_443_2014.pdf

MMA - Ministério do Meio Ambiente. (2012). Unidades de conservação. https://antigo.mma.gov.br/ouvidoria/itemlist/category/34-unidades-de-conservacao .html

MMA - Ministério do Meio Ambiente / IBAMA - Instituto Brasileiro de Meio Ambiente e dos Recursos Naturais Renováveis. (2005). Plano de Manejo da Floresta Nacional do Jamari - Rondônia. MMA/IBAMA.

Moro, M. F., \& Martins, F. R. (2011). Métodos de levantamento do componente arbóreo-arbustivo. In: Felfili, J. M., Eisenlohr, P. V., Melo, M. M. R. F., Andrade, L. A., \& Meira-Neto, J. A. A. Fitossociologia no Brasil - Métodos e estudos de casos. Universidade Federal de Viçosa.

Natividade, M. M., Sampaio, J. S., Pereira, W. S., Sousa, I. R. L., Cardoso Júnior, C. D., Carvalho, C. S. S., \& Melo, L. O. (2018). Estrutura e dinâmica florestal, antes e após extração de madeira, em área de manejo florestal na FLONA do Tapajós. Revista Agroecossistemas, 10(2), 113-124. $10.18542 /$ ragros.v10i2.5183

Oliveira, A. N. D., \& Amaral, I. L. D. (2005). Aspectos florísticos, fitossociológicos e ecológicos de um sub-bosque de terra firme na Amazônia Central, Amazonas, Brasil. Acta Amazonica, 35(1), 1-16. 10.1590/S0044-59672005000100002

Pinheiro, K. A. O., Ruschel, A. R., Carneiro, F. S., Frazão, A. S., Souza, M. F. S., D’Arace, L. M. B., \& Amorim, M. B. (2021). Potential of commercial species analyzed by the importance value index in a reduced impact exploration area. Research, Society and Development, 10(2), 1-11. 10.33448/rsdv10i2.12288

SEDAM - Secretaria de Estado do Desenvolvimento Ambiental. (2012). Boletim Climatológico de Rondônia 2010. SEDAM

SFB - Serviço Florestal Brasileiro. (2020). Floresta Nacional do Jamari. http://www.florestal.gov.br/florestas-sob-concessao/92-concessoes-florestais /florestas-sob-concessao/101-floresta-nacional-do-jamari-ro

SFB - Serviço Florestal Brasileiro. (2016). Nota Técnica sobre o Inventário Florestal da FLONA Jamari. https://www.florestal.gov.b r/documentos/concessoes-florestais/concessoes-florestais-florestas-sob-concessao/flona-do-jamari/edital/204-anexo-6-resumo-inventario/file

Shepherd, G. J. (2010). Manual de usuário FITOPAC 1. UNICAMP

Silva, J. N. M., Lopes, J. C. A., Oliveira, L. C., Silva, S. M. A., Carvalho, J. O. P., Costa, D. H. M., Melo, M. S., \& Tavares, M. J. M. (2005). Diretrizes para a instalação e medição de parcelas permanentes em florestas naturais da Amazônia Brasileira. EMBRAPA Amazônia Oriental. https://ainfo.cnptia.embrapa.br/digital/bitstream/item/205499/1/Diretrizes-para-instalacao-e-medicao-de.pdf

Silva, K. E., Souza, C. R., Azevedo, C. P., \& Rossi, L. M. B. (2015). Dinâmica florestal, estoque de carbono e fitossociologia de uma floresta densa de terrafirme na Amazônia Central. Scientia Forestalis, 43(105), 193-201. https://www.alice.cnptia.embrapa.br/alice/bitstream/doc/1016281/1/cap19.pdf

Souza, A. L., \& Soares, C. P. B. (2013). Florestas Nativas. Editora UFV.

Souza, E. M., \& Sccoti, M. S. V. (2020). Influência da Exploração Florestal nas Populações de Espécies Ameaçadas de Extinção na FLONA do Jamari, RO. Biodiversidade Brasileira, 10(3), 64-73. 10.37002/biobrasil.v10i3.1637

Townsend, C.R., Begon, M., \& Harper, J. L. (2006). Fundamentos em Ecologia. Artmed.

Veloso, H. P., Rangel-Filho, A. L. R., \& Lima, J. C. A. (1991). Classificação da vegetação brasileira, adaptada a um sistema universal. IBGE. https://biblioteca.ibge.gov.br/visualizacao/monografias/GEBIS\%20-\%20RJ/classificacaovegetal.pdf 